\title{
Adaptive Neural PLL for Grid-connected DFIG Synchronization
}

\author{
Ali Bechouche*, Djaffar Ould Abdeslam ${ }^{\dagger}$, Tahar Otmane-Cherif ${ }^{*}$, and Hamid Seddiki ${ }^{*}$ \\ *L2CSP Laboratory, Mouloud Mammeri University of Tizi-Ouzou, Tizi-Ouzou, Algeria \\ ${ }^{\dagger}$ MIPS Laboratory, Haute Alsace University, Mulhouse, France
}

\begin{abstract}
In this paper, an adaptive neural phase-locked loop (AN-PLL) based on adaptive linear neuron is proposed for grid-connected doubly fed induction generator (DFIG) synchronization. The proposed AN-PLL architecture comprises three stages, namely, the frequency of polluted and distorted grid voltages is tracked online; the grid voltages are filtered, and the voltage vector amplitude is detected; the phase angle is estimated. First, the AN-PLL architecture is implemented and applied to a real three-phase power supply. Thereafter, the performances and robustness of the new AN-PLL under voltage sag and two-phase faults are compared with those of conventional PLL. Finally, an application of the suggested AN-PLL in the grid-connected DFIG-decoupled control strategy is conducted. Experimental results prove the good performances of the new AN-PLL in grid-connected DFIG synchronization.
\end{abstract}

Key words: Adaptive linear neuron (ADALINE), Decoupled $P-Q$ control, Doubly fed induction generator (DFIG), Phase-locked loop (PLL), Synchronization

\section{NOMENCLATURE}

$v_{a s}, v_{b s}, v_{c s}, v_{a r}, \quad$ Stator and rotor $a-, b$-, $c$-phase voltages.

$v_{b r}, v_{c r}$

$i_{a s}, i_{b s}, i_{c s}, i_{a r}, i_{b r}$, Stator and rotor $a-, b$-, c-phase currents.

$i_{c r}$

$U_{g}$

$V_{d s}, V_{q s}, V_{d r}, V_{q r}$

$I_{d s}, I_{q s}, I_{d r}, I_{q r}$

$\varphi_{d s}, \varphi_{q s}, \varphi_{d r}, \varphi_{q r}$

$L_{s}, L_{r}$

$M$

$R_{s}, R_{r}$

$T_{s}, T_{r}$

$\sigma=1-M^{2} /\left(L_{s} L_{r}\right)$

$T_{e m}$

$p$

$\omega_{s}, \omega, \omega_{r}$

$P, Q$
Grid voltage vector amplitude.

Stator and rotor $d-q$ voltages.

Stator and rotor $d-q$ currents.

Stator and rotor $d-q$ flux.

Stator and rotor cyclic inductances.

Mutual inductance.

Stator and rotor resistances.

Stator and rotor time constants.

Leakage factor.

Electromagnetic torque.

Number of pole pairs.

Synchronous, rotor, and slip speeds.

Active and reactive powers.

Manuscript received Jun. 6, 2013; accepted Mar. 10, 2014

. Recommended for publication by Associate Editor Kyo-Beum Lee.

${ }^{\dagger}$ Corresponding Author: djaffar.ould-abdeslam@uha.fr

Tel: +33 03893360 20, Fax: +33 03893360 84, Haute-Alsace Univ.

*L2CSP Laboratory, Mouloud Mammeri Univ. of Tizi-Ouzou, Algeria
$s, r$
Subscripts indicating stator and rotor.
$d, q$
$T_{e}$ Synchronous reference frame.
Sampling period.

\section{INTRODUCTION}

Doubly fed induction generator (DFIG) is highly attractive for wind energy generation, in which this generator is driven by wind turbine, and its stator is directly connected to grid. DFIG rotor winding is connected to a back-to-back power converter that provides variable-frequency rotor voltage [1]-[3]. DFIG-based variable speed wind turbines have numerous advantages [4], [5]. First, the maximal mechanical power attainable from wind can be extracted and converted to fixed-frequency electric power by adjusting DFIG speed and electromagnetic torque. Second, only a fraction of the nominal electric power passes through the power converters, thus reducing its loss and cost. Third, stator active and reactive powers can be independently controlled.

Conventional control system of DFIGs is based on stator-flux-oriented vector control [6]-[9]. The proper synchronization with the reference grid is one of the most important aspects to consider in grid-connected DFIG control. The most widely accepted solutions to provide this synchronization are the phase-locked loop (PLL) techniques 
[10]. In conventional control strategies of DFIG, the amplitude, frequency, and phase angle of positive-sequence grid voltages are necessary. These quantities are mainly used for synchronization of the system output variables, power flux calculations, or transformation of state variables into rotating reference frame coordinates [11].

The most used technique for grid-connected converter synchronization is the conventional three-phase PLL based on synchronous reference frame (SRF). This technique uses Concordia's and Park's transformations to translate the three-phase voltage vector from the natural reference frame to the rotating one. Conventional PLL technique provides acceptable results under ideal utility conditions. However, this technique is inefficient in the presence of unbalanced grid voltages [10], [11]. To overcome this limitation, several PLL algorithms with different characteristics have been developed and presented in the literature recently. A PLL based on adaptive linear optimal filter technique was presented in [11]. The authors in [12] proposed a filtered-sequence PLL structure using Park transformation and moving average filters. A synchronization method derived from the standard PLL based on $p q$ theory with a control model using standard $q$ PLL structure was provided in [13]. A selective harmonic detection system based on three-phase cascaded delayed signal cancellation PLL was developed in [14]. A PLL based on variable sampling period concept, which allows the automatic adjustment of sampling frequency, was proposed in [15]. In [16], the authors proposed an adaptive SRF-PLL that rejects voltage disturbances by using several adaptive infinite-impulse-response notch filters. Another adaptive PLL structure based on adaptively adjusting the gain of frequency estimation loop was developed in [17] to minimize false frequency transients. In [18], a generalized delayed signal cancellation PLL method was proposed. In [19], a frequency-locked loop dual second-order generalized integrator based on two adaptive filters was implemented on a stationary reference frame.

PLL performances depend on the computational cost of the used algorithms and their immunity to faults. To improve the robustness of the PLL architecture without increasing the computational cost, a new adaptive neural PLL (AN-PLL) for grid-connected DFIG synchronization is developed in this study. The proposed AN-PLL architecture is based on adaptive linear neuron (ADALINE) networks, which are successfully applied to several fields, such as network frequency tracking [20], [21], current harmonic estimation [22], and induction motor parameter identification [23], [24]. The main advantages of the proposed AN-PLL are its accuracy, robustness, and adaptive structure. This AN-PLL can accurately estimate the frequency in polluted and distorted utility conditions to filter grid voltages and to reconstitute the voltage vector amplitude. The phase angle of power supply is detected using a unitary three-phase system obtained from the grid voltage positive sequences.

The remaining of this paper is divided into seven sections. Section II presents the grid-connected DFIG model and decoupled $P-Q$ control strategy. Section III provides voltage frequency estimation using pseudo-square ADALINE in the presence of harmonic distortion. Section IV demonstrates grid voltage filtering by ADALINE and PLL for phase angle estimation. Section V elucidates the performance comparison between the proposed AN-PLL and the conventional PLL in severe utility conditions. Section VI discusses an application of the new AN-PLL in the decoupled $P-Q$ control scheme of the grid-connected DFIG. Finally, Section VII concludes.

\section{MODELING AND DECOUPLING $P-Q$ CONTROL OF THE GRID-CONNECTED DFIG}

\section{A. Modeling of the DFIG}

In $d-q$ Park reference frame, the DFIG electric equations can be written as follows:

$$
\begin{aligned}
& V_{d s}=R_{s} I_{d s}+\frac{d \varphi_{d s}}{d t}-\omega_{s} \varphi_{q s}, \\
& V_{q s}=R_{s} I_{q s}+\frac{d \varphi_{q s}}{d t}+\omega_{s} \varphi_{d s}, \\
& V_{d r}=R_{r} I_{d r}+\frac{d \varphi_{d r}}{d t}-\omega_{r} \varphi_{q r}, \\
& V_{q r}=R_{r} I_{q r}+\frac{d \varphi_{q r}}{d t}+\omega_{r} \varphi_{d r},
\end{aligned}
$$

with

$$
\begin{aligned}
& \varphi_{d s}=L_{s} I_{d s}+M I_{d r}, \\
& \varphi_{q s}=L_{s} I_{q s}+M I_{q r}, \\
& \varphi_{d r}=L_{r} I_{d r}+M I_{d s}, \\
& \varphi_{q r}=L_{r} I_{q r}+M I_{q s} .
\end{aligned}
$$

The stator and rotor angular speeds are linked by the following relationship:

$$
\omega_{s}=\omega_{r}+\omega .
$$

The DFIG electromagnetic torque is expressed by the stator flux and the rotor currents as follows:

$$
T_{e m}=p M\left(\varphi_{q s} I_{d r}-\varphi_{d s} I_{q r}\right) / L_{s} .
$$

Finally, the stator and rotor active and reactive powers can be written as follows:

$$
\begin{aligned}
& P_{s}=V_{d s} I_{d s}+V_{q s} I_{q s}, \\
& Q_{s}=V_{q s} I_{d s}-V_{d s} I_{q s}, \\
& P_{r}=V_{d r} I_{d r}+V_{q r} I_{q r}, \\
& Q_{r}=V_{q r} I_{d r}-V_{d r} I_{q r} .
\end{aligned}
$$

\section{B. Decoupled P-Q Control of the DFIG}

To simplify Equation (4), as well as the DFIG control, a 
stator flux orientation according to $d$-axis is chosen, that is, $\varphi_{d s}=\varphi_{s}$ and $\varphi_{q s}=0$ [2], [5]. Equation (4) then becomes

$$
T_{e m}=-p M \varphi_{d s} I_{q r} / L_{s} .
$$

By choosing $d-q$ Park reference frame related to the stator flux and by neglecting stator resistances, (1) becomes

$$
\begin{gathered}
V_{d s}=0, \\
V_{q s}=U_{g}=\omega_{s} \varphi_{d s}, \\
V_{d r}=R_{r} I_{d r}+\frac{d \varphi_{d r}}{d t}-\omega_{r} \varphi_{q r}, \\
V_{q r}=R_{r} I_{q r}+\frac{d \varphi_{q r}}{d t}+\omega_{r} \varphi_{d r} .
\end{gathered}
$$

By replacing $\varphi_{d r}$ and $\varphi_{q r}$ in (7.c) and (7.d),

$$
\begin{gathered}
V_{d r}=R_{r} I_{d r}+\sigma L_{r} \frac{d I_{d r}}{d t}-\omega_{r} \sigma L_{r} I_{q r}, \\
V_{q r}=R_{r} I_{q r}+\sigma L_{r} \frac{d I_{q r}}{d t}+\omega_{r} \sigma L_{r} I_{d r}+\omega_{r} \frac{M}{L_{s}} \varphi_{d s} .
\end{gathered}
$$

The stator active and reactive powers can be reconstructed from the rotor currents and stator flux as follows [3], [9]:

$$
\begin{gathered}
P_{s}=-V_{q s} \frac{M}{L_{s}} I_{q r}, \\
Q_{s}=V_{q s} \frac{\varphi_{d s}}{L_{s}}-V_{q s} \frac{M}{L_{s}} I_{d r} .
\end{gathered}
$$

Equation (6) indicates that the stator flux orientation according to $d$-axis permits to obtain an electromagnetic torque; therefore, the stator active power is proportional to $q$-axis rotor current. The stator reactive power is proportional to $d$-axis rotor current with a constant imposed by the grid.

The stator powers can be controlled independently, as confirmed by the DFIG model given by (8). Each rotor current can be regulated with its own controller. To perform independent control, two proportional-integral (PI) controllers are used. The block diagram of the rotor current regulation is presented in Fig. 1.

\section{PSEUDO-SQUARE ADALINE FOR VOLTAGE FREQUENCY ESTIMATION}

In this section, the required objective is to estimate online the fundamental frequency of a sinusoidal voltage corrupted by noise and harmonic distortions. This objective is achieved by a pseudo-square ADALINE [21].

ADALINE was introduced for frequency estimation [20]. This approach has been used to identify the voltage parameters written as

$$
v(k)=\sum_{n=1}^{\infty} A_{n} \sin \left(\omega_{n} k T_{e}+\varphi_{n}\right),
$$

where $A_{n}, \omega_{n}$, and $\varphi_{n}$ are the amplitude, pulsation, and phase of $n^{\text {th }}$ term, respectively. The recursive expression of $v(k)$ can be deduced as follows:

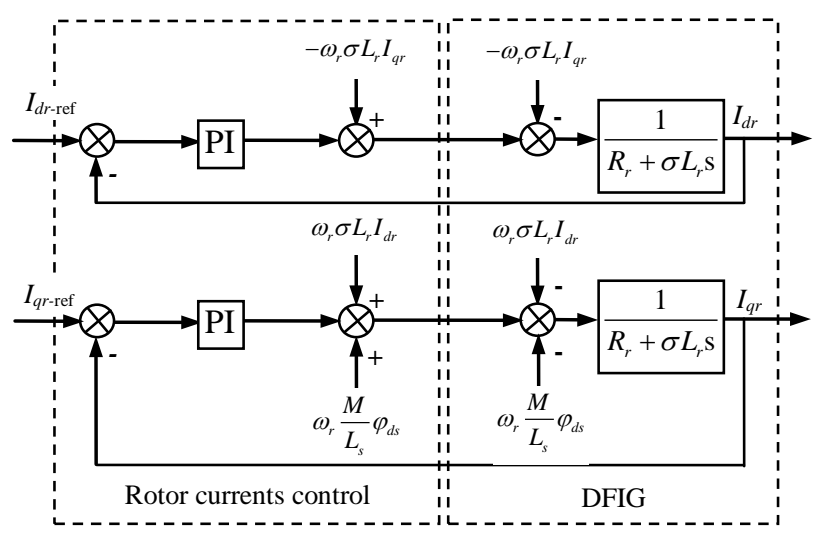

Fig. 1. Block diagram of the rotor current control.

$$
\begin{aligned}
v(k+1)+v(k-1) & =\sum_{n=1}^{\infty} A_{n} \sin \left(\omega_{n} k T_{e}+\varphi_{n}\right) \cdot 2 \cos \left(\omega_{n} T_{e}\right) \\
& =2 \cos \left(\omega_{n} T_{e}\right) \cdot v(k) .
\end{aligned}
$$

If the harmonics are neglected, the voltage signal $v(k)$ can be rewritten as

$$
v(k)=2 \cos \left(\omega_{1} T_{e}\right) \cdot v(k-1)-v(k-2) .
$$

Fig. 2 shows that by tacking the vector $X(k)=[v(k-1)$ $v(k-2)]^{T}$ as input of ADALINE, after convergence, its weight vector $W(k)=\left[w_{1}(k) w_{2}(k)\right]$ will adapt and converge toward the vector $R(k)=\left[2 \cos \left(\omega_{1}(k) T_{e}\right)-1\right]$. The least mean square algorithm with the learning rate $\eta$ is used for weight training [20]-[24].

ADALINE weight vector $\quad W(k)=\left[w_{1}(k) \quad w_{2}(k)\right] \quad$ is recursively updated as follows:

$$
W(k+1)=W(k)+\frac{\eta e(k) X^{T}(k)}{\varepsilon+X^{T}(k) X(k)},
$$

where $X(k)=[v(k-1) \quad v(k-2)] \quad$ is the input vector, $e(k)=v(k)-v_{\text {est }}(k)$ is the estimation error, $\eta$ is the learning rate, and $\varepsilon$ is a small value used to avoid division by zero if $X^{\mathrm{T}}(k) X(k)=0$.

To prove the stability of the frequency estimator (ADALINE), Lyapunov function candidate for the frequency estimator (13) is used. This function is selected as

$$
V(k)=\tilde{W}^{T}(k) \tilde{W}(k),
$$

where $\tilde{W}(k)$ is ADALINE estimation error, which is defined as

$$
\tilde{W}(k) \equiv R(k)-W(k) .
$$

Lyapunov's convergence criterion must be satisfied, such that

$$
V(k) \Delta V(k)<0,
$$

where $\Delta V(k)$ is the change in the Lyapunov function. This change is given by

$$
\Delta V(k)=V(\tilde{W}(k+1))-V(\tilde{W}(k))<0 .
$$

By using the frequency estimator error dynamics, which can 


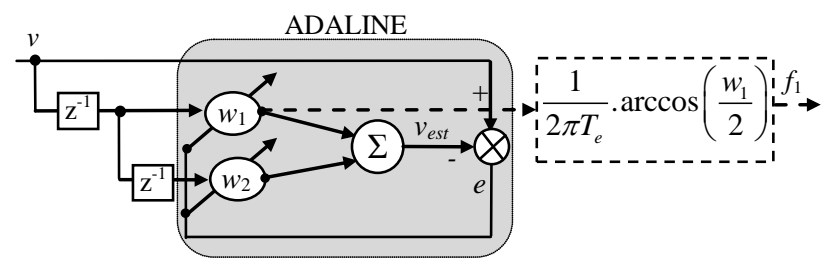

Fig. 2. ADALINE for frequency tracking.

be derived using (15), with the update law (13), $\Delta V(k)$ can be evaluated as

$$
\begin{aligned}
\Delta V(k) & =\left\|\tilde{W}(k)-\frac{\eta X^{T}(k) X(k) \tilde{W}(k)}{\varepsilon+X^{T}(k) X(k)}\right\|^{2}-\tilde{W}^{T}(k) \tilde{W}(k) \\
& =\frac{\eta\left[\tilde{W}^{T}(k) X(k)\right]^{2}}{\varepsilon+X^{T}(k) X(k)} \cdot\left[-2+\frac{\eta X^{T}(k) X(k)}{\varepsilon+X^{T}(k) X(k)}\right] .
\end{aligned}
$$

Assuming that $\varepsilon>0$ and $0<\eta<2$, the bracketed term in (18) is negative. Consequently, the stability condition in (17) is satisfied, as well as the following convergence properties:

$$
\begin{gathered}
\left\|R(k)-R_{0}\right\| \leq\left\|R(k-1)-R_{0}\right\| \leq\left\|R(0)-R_{0}\right\|, k \geq 1, \\
\lim _{k \rightarrow \infty} \frac{X(k) \tilde{W}^{T}(k)}{\sqrt{\varepsilon+X^{T}(k) X(k)}}=0,
\end{gathered}
$$

where $R_{0}$ is the vector obtained at the perfect convergence of the estimator. According to (19), the augmented error is monotonically non-increasing; therefore, the convergence is guaranteed, and the weight $w_{1}$ will be converged to $2 \cos \left(\omega_{1}(k) T_{e}\right)$. At each iteration, the voltage signal frequency can hence be reconstructed online in the following way:

$$
f_{1}=\frac{1}{2 \pi T_{e}} \cdot \arccos \left(\frac{w_{1}}{2}\right) \text {. }
$$

A main advantage of this method is its immunity to the voltage signal amplitude and phase variation or disturbance. A proof of weight convergence of ADALINE can be found in [20].

However, the sampling period $T_{e}$ greatly influences the performances of this approach. The estimated frequency $f_{1}$ depends on the sampling period $T_{e}$. In the presence of harmonics, the function arccos in (20) is sensitive to weight variation. Fig. 3 shows the weight value $w_{1}$ according to $T_{e}$ for a $50 \mathrm{~Hz}$ grid frequency. This figure indicates that $T_{e}=5 \mathrm{~ms}$ represents a good choice because it corresponds to $w_{1}=0$, which is the center of the range $[+2,-2]$. Fig. 4 shows the relationship between the frequency and the weight $w_{1}$ for various $T_{e}$ values. The maximum variation of the weight is obtained with an adequate sampling period $T_{e}=1 / 4 f_{1}$ for $w_{1}=0$. An example is delivered for $f_{1}=50 \mathrm{~Hz}$ in this figure. Consequently, the sampling period of $T_{e}=1 / 4 f_{1}$ is chosen to maximize the dynamics and ensure the system stability. The choice of $T_{e}=1 / 4 f_{1}$ removes a part of the existing harmonics in the voltage. In our case, all the frequencies superior to

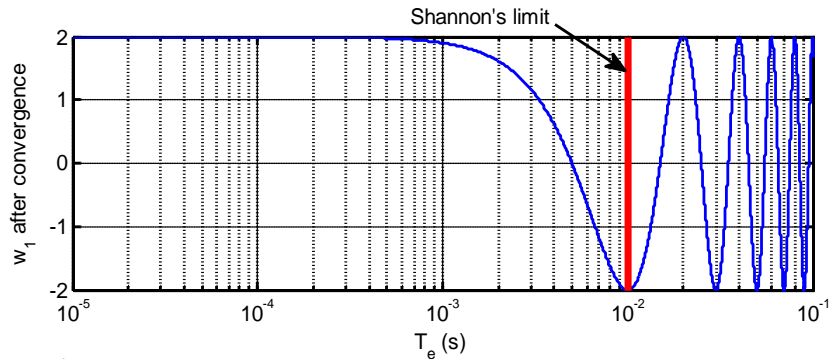

Fig. 3. $T_{e}$ influence on the weight $w_{1}$ convergence value.

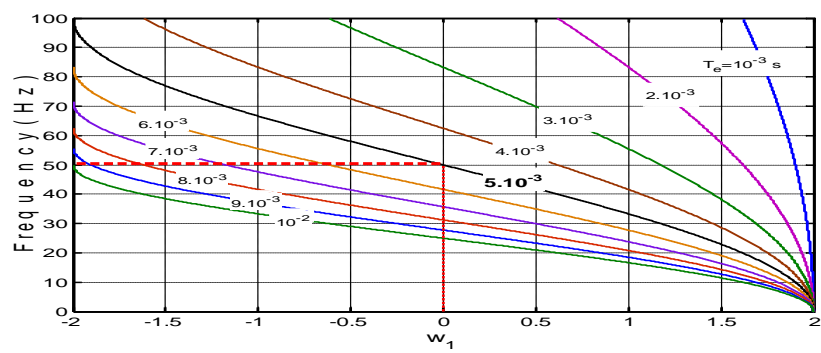

Fig. 4. Observable frequency as a function of $w_{1}$ for different values of $T_{e}$.

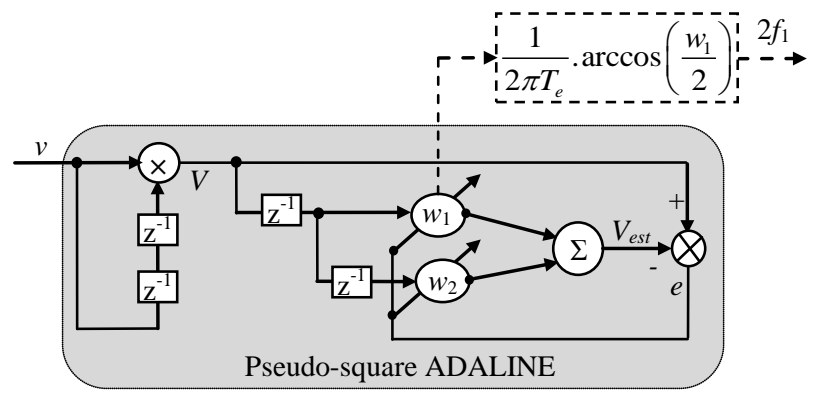

Fig. 5. Frequency estimator based on the pseudo-square ADALINE.

$100 \mathrm{~Hz}$ will be eliminated for $T_{e}=5 \mathrm{~ms}$.

In [21], ADALINE was concluded to be inadequate in the presence of harmonics. To improve the frequency estimation performance in polluted and distorted voltages, an alternative of this approach is proposed. Pre-multiplication of $v(k)$ with $v(k-D)$ is conducted before performing calculations to accentuate the difference between two signals in close frequencies over one period, where $D$ is the number of the delayed sampling periods. Thus, the new voltage signal $V(k)$ at ADALINE input is

$$
\begin{aligned}
& V(k)=v(k) \cdot v(k-D) \\
& =\frac{A_{1}^{2}}{2}\left[\alpha\left\{1-\cos \left(2 \omega_{1} k T_{e}+2 \varphi_{1}\right)\right\}-\beta \sin \left(2 \omega_{1} k T_{e}+2 \varphi_{1}\right)\right]
\end{aligned}
$$

with $\alpha=\cos \left(\omega_{1} D T_{e}\right)$ and $\beta=\sin \left(\omega_{1} D T_{e}\right)$. If $T_{e}=1 /\left(4 f_{1}\right)=2.5 \mathrm{~ms}$ and $D=d / T_{e}$, with $d$ selected to be equal to $T / 4=5 \mathrm{~ms}$ ( $f=50 \mathrm{~Hz}$ ), $\alpha$ becomes negligible compared with $\beta$ for frequencies close to $50 \mathrm{~Hz}$. Thus, the voltage signal $V(k)$ can be written in the following form: 


$$
V(k)=-\frac{A_{1}^{2}}{2} \sin \left(2 \omega_{1} k T_{e}+2 \varphi_{1}\right) .
$$

By using ADALINE and following the same procedure as illustrated in Fig. 2, the polluted and distorted voltage frequencies can be estimated from the weight $w_{1}$. The principle scheme is illustrated in Fig. 5. This frequency will be used in the grid voltage filtering process developed in the following section.

\section{ADALINE FOR GRID VOLTAGE FILTERING AND PLL FOR PHASE ANGLE DETECTION}

\section{A. ADALINE for Grid Voltage Filtering}

A grid voltage filtering using ADALINE networks is presented. The idea is to conduct a suitable decomposition of the measured voltage and estimate its positive-sequence component. Thereafter, this component will be transformed in an adequate form to be learned by ADALINE.

The proposed filtering method applied to the phase $a$ is developed. This methodology can be easily generalized to the phases $b$ and $c$. The measured grid voltage contains a fundamental component and harmonics. In discrete form, the voltage $v_{a}(k)$ can be written as follows:

$$
\begin{aligned}
V_{a}(k) & =\sum_{n=1}^{\infty} \sqrt{2} V_{a n} \cos \left(\omega_{n} k T_{e}+\varphi_{n}\right) \\
& =\sqrt{2} V_{a 1} \cos \left(\omega_{1} k T_{e}+\varphi_{1}\right)+\sum_{n=2}^{\infty} \sqrt{2} V_{a n} \cos \left(\omega_{n} k T_{e}+\varphi_{n}\right)
\end{aligned}
$$

where $V_{a n}$ is the root mean square value of $n^{\text {th }}$ term, with $\omega_{n}$ as its pulsation and $\varphi_{n}$ as its phase. The filtering process of this voltage consists of extracting the positive-sequence component. After filtering, (23) becomes

$$
v_{a}(k)=\sqrt{2} V_{a 1} \cos \left(\omega_{1} k T_{e}+\varphi_{1}\right)
$$

This equation can also be written in the following explicit form:

$$
\begin{aligned}
V_{a}(k)= & \sqrt{2} V_{a 1} \cos \left(\varphi_{1}\right) \cdot \cos \left(\omega_{1} k T_{e}\right) \\
& -\sqrt{2} V_{a 1} \sin \left(\varphi_{1}\right) \cdot \sin \left(\omega_{1} k T_{e}\right) .
\end{aligned}
$$

Thus, (25) can be expressed in vectorial notation as follows:

$$
v_{a}(k)=W_{a}^{T} X(k),
$$

with

$$
\begin{aligned}
& W_{a}^{T}=\left[\begin{array}{ll}
W_{a 1} & w_{a 2}
\end{array}\right]=\left[\begin{array}{ll}
\sqrt{2} V_{a 1} \cos \left(\varphi_{1}\right) & -\sqrt{2} V_{a 1} \sin \left(\varphi_{1}\right)
\end{array}\right], \\
& X(k)=\left[\begin{array}{l}
\cos \left(\omega_{1} k T_{e}\right) \\
\sin \left(\omega_{1} k T_{e}\right)
\end{array}\right] .
\end{aligned}
$$

One ADALINE with two adaptive weights is able to estimate (26). $X(k)$ represents the input vector composed of two generated sine waves with unity amplitude and frequency $f_{1}=\omega_{1} / 2 \pi . W_{a}{ }^{T}$ represents the weight vector. The voltage

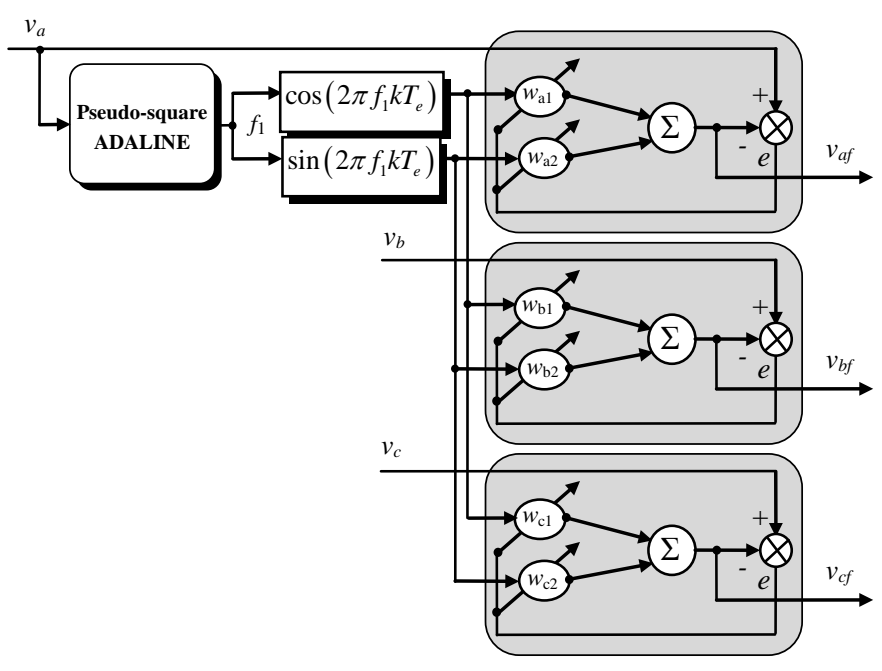

Fig. 6. ADALINE for grid voltage filtering.

fundamental frequency $f_{1}$ is obtained using the previously developed strategy (Section III).

For the phases $b$ and $c$, the obtained vectorial notations are respectively given as follows:

$$
\begin{aligned}
& v_{b}(k)=W_{b}^{T} X(k), \\
& v_{c}(k)=W_{c}^{T} X(k),
\end{aligned}
$$

with

$$
\begin{aligned}
& W_{b}^{T}=\left[w_{b 1} w_{b 2}\right]=\left[\sqrt{2} V_{b 1} \cos \left(\varphi_{1}-\frac{2 \pi}{3}\right)-\sqrt{2} V_{b 1} \sin \left(\varphi_{1}-\frac{2 \pi}{3}\right)\right], \\
& W_{c}^{T}=\left[w_{c 1} w_{c 2}\right]=\left[\sqrt{2} V_{c 1} \cos \left(\varphi_{1}-\frac{4 \pi}{3}\right)-\sqrt{2} V_{c 1} \sin \left(\varphi_{1}-\frac{4 \pi}{3}\right)\right] .
\end{aligned}
$$

After filtering, sinusoidal three-phase voltages are obtained. The resulting amplitudes are equal to the fundamental amplitudes of each phase. These filtered voltages can be written in the following form:

$$
\begin{aligned}
& v_{a f}(k)=\sqrt{2} V_{a 1} \cos \left(\omega_{1} k T_{e}+\varphi_{1}\right), \\
& v_{b f}(k)=\sqrt{2} V_{b 1} \cos \left(\omega_{1} k T_{e}+\varphi_{1}-\frac{2 \pi}{3}\right), \\
& v_{c f}(k)=\sqrt{2} V_{c 1} \cos \left(\omega_{1} k T_{e}+\varphi_{1}-\frac{4 \pi}{3}\right) .
\end{aligned}
$$

The filtering scheme of the grid voltages $v_{a}, v_{b}$, and $v_{c}$ using the proposed strategy is shown in Fig. 6. These voltages will be used in the following subsection for phase angle detection.

\section{B. PLL for Phase Angle Detection}

Before detecting the phase angle of the filtered voltages using a PLL, a new unitary three-phase system is applied to (30). Each voltage is divided by its amplitude. Consequently, 


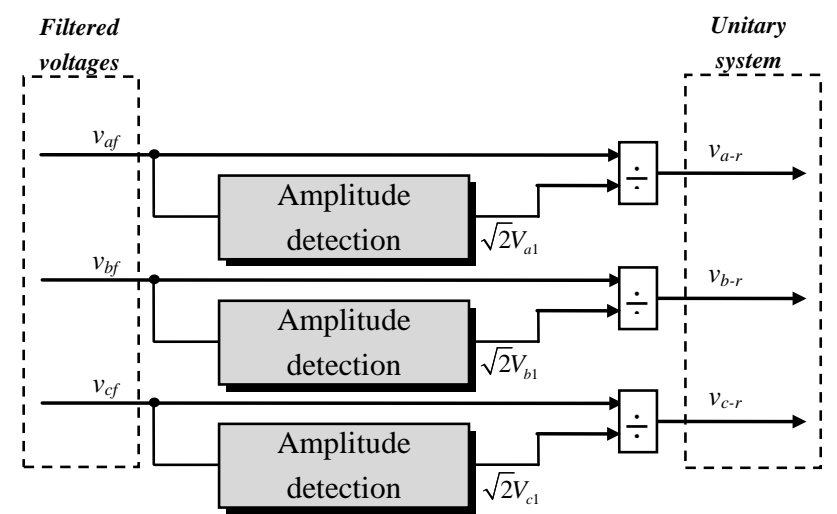

(a)

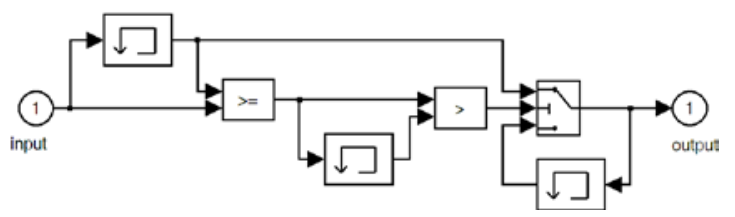

(b)

Fig. 7. (a) Unitary three-phase system determination and (b) amplitude detection algorithm of the grid voltages.

a sinusoidal and balanced three-phase system with unit amplitude is obtained. This new system is independent on the grid voltage levels and is in phase. By applying this principle to (30), a sinusoidal and balanced unitary three-phase system is computed as follows:

$$
\begin{aligned}
& v_{a-r}(k)=\sqrt{2} V_{a-r} \cos \left(\omega_{1} k T_{e}+\varphi_{1}\right), \\
& v_{b-r}(k)=\sqrt{2} V_{b-r} \cos \left(\omega_{1} k T_{e}+\varphi_{1}-\frac{2 \pi}{3}\right), \\
& v_{c-r}(k)=\sqrt{2} V_{c-r} \cos \left(\omega_{1} k T_{e}+\varphi_{1}-\frac{4 \pi}{3}\right) .
\end{aligned}
$$

with $\sqrt{2} V_{a-r}=\sqrt{2} V_{b-r}=\sqrt{2} V_{c-r}=\sqrt{2} V_{r}=1$.

The grid voltage amplitudes are detected by using an envelope detector available in MATLAB-Simulink library. The amplitude detector algorithm aims to detect the periodic signal amplitude. This detection is based on a switch block that sends the greater value of that obtained at times $k T_{e}$ and $(k-1) T_{e}$ to the output. In this work, the proposed envelope detector scheme is slightly extended for negative signals. The block diagram of the unitary three-phase system determination and the amplitude detection algorithm schemes are shown in Fig. 7.

Thereafter, the obtained three-phase system (31) can be applied to a PLL to determine accurately the phase angle. The principle diagram of the PLL is presented in Fig. 8. The PLL uses a fundamental property of Park's transformation [11]. If the estimated pulsation $\omega_{\text {est } 1}$ used in the transformation is equal to the balanced three-phase system pulsation $\omega_{1}$, then $d$ - and $q$-axis components are constant. The obtained sinusoidal three-phase system (31) is translated via

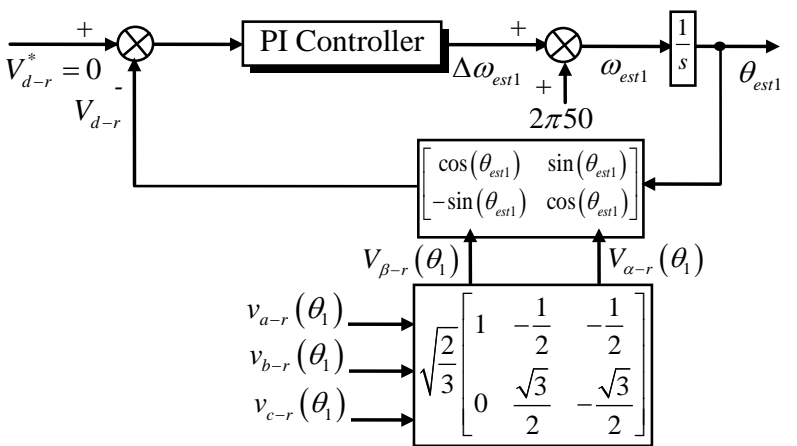

Fig. 8. PLL principle scheme for phase angle detection from the unitary three-phase system.

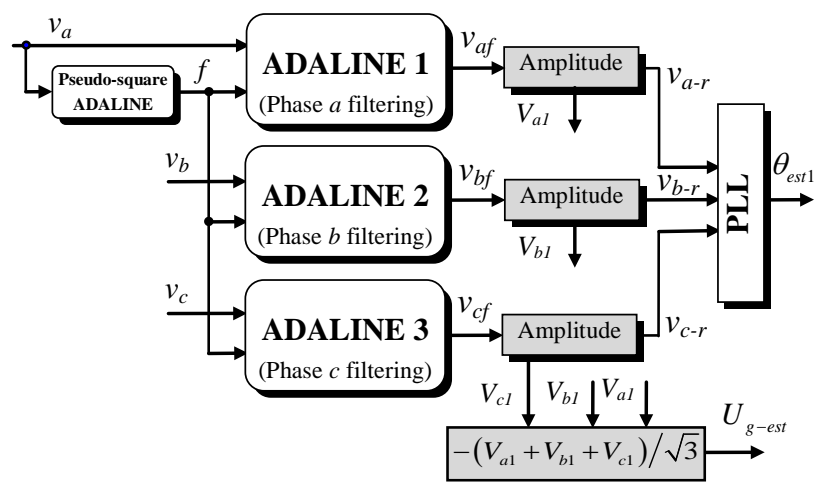

Fig. 9. Complete scheme principle of the proposed AN-PLL.

Concordia's transformation. The estimated angle $\theta_{\text {est1 }}$ of Park's rotation is performed by integrating $\omega_{\text {est } 1}$ obtained by PI controller. The pulsation $\omega_{\text {est } 1}$ must be identical to $v_{a b c-r}\left(\theta_{1}\right)$ pulsation. The amplitude of the controlled $V_{d-r}$ determines the shift between $V_{r}$ value and $\sin \left(\theta_{1}\right)$. The difference in the phase will be controlled by $V_{d-r}^{*}$. The PLL will be locked when the estimated angle $\theta_{\text {est } 1}$ is equal to $\theta_{1}$. This condition is realized if $V_{d-r}^{*}$ is maintained equal to zero. To achieve good performances by this PLL, the three-phase system must be sinusoidal and balanced. To this end, the voltages are filtered and transformed into a unitary three-phase system. PI parameters are calculated by considering the linearized model for small variations in $\theta_{1}$. As the grid voltage vector is maintained according to $q$-axis, its amplitude can be estimated from the detected amplitudes of $a, b$, and $c$ phases in the following way (given as a negative quantity):

$$
U_{g-e s t}=-\left(V_{a 1}+V_{b 1}+V_{c 1}\right) / \sqrt{3} \text {. }
$$

The block diagram of the suggested AN-PLL strategy is shown in Fig. 9. The blocks "Amplitude" (described in Fig. 7) divide the input voltages by their amplitudes.

\section{EXPERIMENTAL VERIFICATION OF THE PROPOSED AN-PLL}

To verify and compare the suggested AN-PLL 
performance with the conventional PLL, an experiment is conducted. A DS1104 dSPACE board based on TMS320F240 floating point DSP is used. The proposed AN-PLL and the conventional PLL algorithms are implemented under MATLAB-Simulink with a sampling period of $0.1 \mathrm{~ms}$. In this section, the DFIG wind turbine is not operated. The used conventional PLL is based on SRF [11], as described in Fig. 8. The measured grid voltages are directly applied to this conventional PLL; therefore, no adaptive filter interfacing scheme is inserted at its input.

An experimental comparative study between the AN-PLL and the conventional PLL is presented. The estimated quantities, such as voltage vector amplitude, frequency, and phase angle, are considered as comparison quantities. The measured grid voltages, filtered voltages, and unitary three-phase system are shown to analyze the AN-PLL operation. The learning rates of the used ADALINE networks in the AN-PLL, ensuring an optimal speed of weight convergence, are experimentally adjusted. For the pseudo-square ADALINE, the learning rate is set to 0.04; for the adaptive filtering, the learning rate is set to 0.01 . PI parameters in the PLL are calculated to obtain a response time $t_{r}=10 \mathrm{~ms}$, a damping coefficient $z=1$, and a natural pulsation $\omega_{n}=4.5 \mathrm{rad} / \mathrm{s}$. Two disturbances, namely, voltage sag and two-phase fault, are considered. In the experiment, a performance analysis of the AN-PLL in normal operating conditions (without faults) is first conducted. A comparative study between the AN-PLL and the conventional PLL under severe conditions is then performed. In this study, the grid voltage frequency is unaffected. Only variations in the grid voltage amplitudes are created.

Fig. 10 shows AN-PLL performances under normal operating conditions. The filtered grid voltages [Fig. 10(b)] are in phase with the real measured grid voltages [Fig. 10(a)]. By dividing each filtered voltage by its detected amplitude, a sinusoidal and balanced three-phase system is obtained with unit amplitude and in phase with the grid voltages [Fig. 10(c)]. Thereafter, the detected maximal amplitudes are exploited to estimate the voltage vector amplitude $U_{\text {g-est }}$. As shown in Fig. 10d, the amplitude $U_{g \text {-est }}$ is estimated with high precision and low oscillations caused by frequency fluctuation. This frequency fluctuation, in the grid voltage, affects the calculation in Park's transformation. Hence, small fluctuations are obtained in the calculated $d$ - and $q$-axis components of the grid voltage. The pseudo-square ADALINE conceived to estimate the utility frequency in distortion voltages shows good performances [Fig. 10(e)]. The minor oscillations observed in the estimated frequency are due to the utility frequency fluctuation $( \pm 0.2 \mathrm{~Hz})$, which is acceptable because the tolerance interval in this condition is $\pm 0.5 \mathrm{~Hz}$. The obtained unitary three-phase system, which is given in Fig. 10c, is used to detect the phase angle by a PLL. Fig. 10(f) reveals that the phase angle is well estimated. This
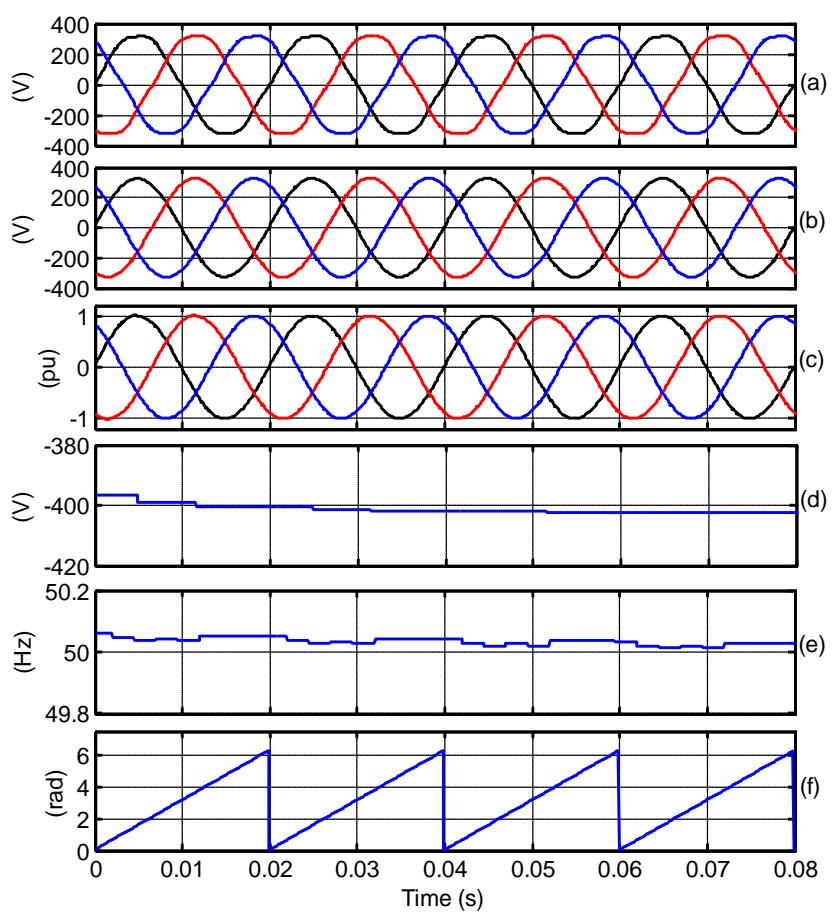

Fig. 10. AN-PLL performances in normal operating conditions. (a) Grid voltages. (b) Filtered grid voltages. (c) Unitary three-phase system. (d) Voltage vector amplitude. (e) Frequency.(f) Phase angle.

result proves the good performance of the proposed AN-PLL strategy under normal operating conditions.

Fig. 11 shows the performance comparison between the conventional PLL and the AN-PLL under 50\% voltage sag. At $\mathrm{t}=0.63 \mathrm{~s}$, a voltage sag appears [Fig. 11(a)], which is generated by multiplying the voltage sensor gains of the phases $a, b$, and $c$ by 0.5 at time $0.63 \mathrm{~s}$. ADALINE-based filter follows perfectly the grid voltages change in steady state. Only $0.1 \mathrm{~s}$ is needed to estimate accurately the positive-sequence components after the disturbance appearance [Fig. 11(b)]. The unitary three-phase system has also been reconstructed in $0.1 \mathrm{~s}$ after disturbance starting [Fig. 11(c)]. The voltage vector amplitude is well estimated with the AN-PLL compared with the conventional PLL [Fig. 11(d)]. However, a transient state is observed in the amplitude estimation in AN-PLL. This transient state is due to ADALINE weight adaptation and learning process following the grid voltage change. Fig. 11(d) shows that voltage sag appears rapidly in the conventional PLL compared with the AN-PLL. However, the main advantage of the proposed AN-PLL is clearly shown in the steady state operation, in which the AN-PLL estimates better the grid voltage parameters than the conventional PLL does. To improve the transient state of the proposed AN-PLL, the sampling period $T_{e}$ used in the implementation must be reduced because according to (13), ADALINE weight learning is performed by iterations. Therefore, using lower sampling period leads to fast learning, and the transient state 


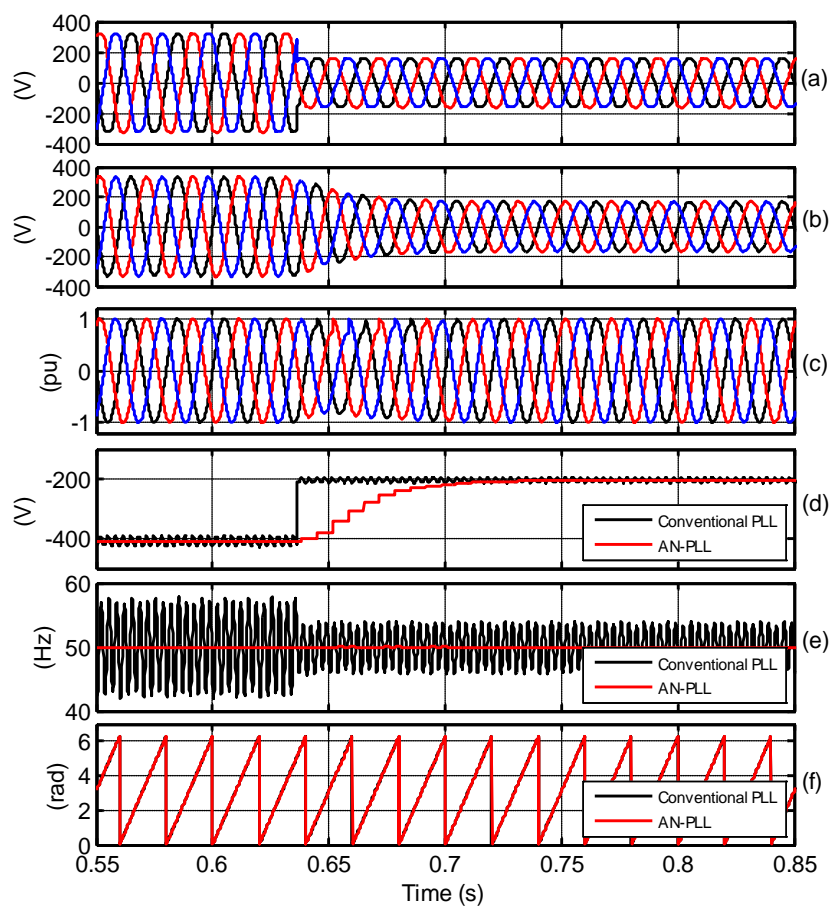

Fig. 11. Comparison between the conventional PLL and the AN-PLL under $50 \%$ voltage sag in grid voltages. (a) Grid voltages. (b) Filtered grid voltages. (c) Unitary three-phase system. (d) Voltage vector amplitude. (e) Frequency. (f) Phase angle.

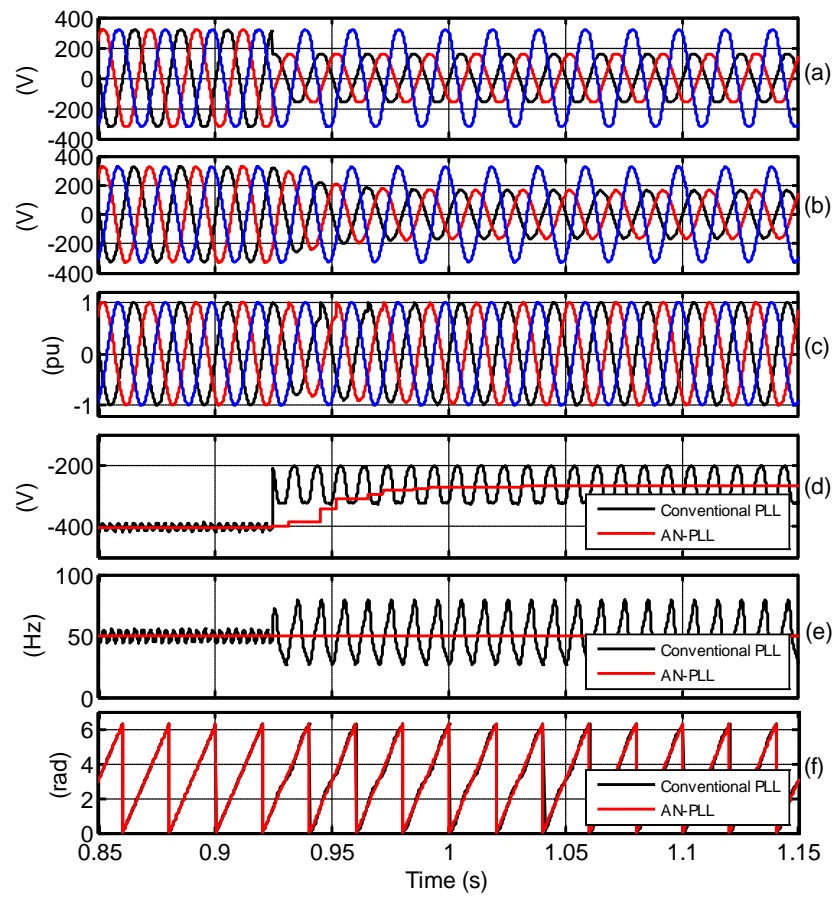

Fig. 12. Comparison between the conventional PLL and the AN-PLL under a two-phase fault: (a) grid voltages, (b) filtered grid voltages, (c) unitary three-phase system, (d) voltage vector amplitude, (e) frequency, and (f) phase angle.

will be reduced. Nevertheless, the estimated utility frequency from the conventional PLL has considerable fluctuation compared with the signal obtained from the AN-PLL [Fig. 11(e)], which remains insensitive to the disturbance. As shown in Fig. 11(f), the estimated phase angle from the conventional PLL is distorted because the angle is directly calculated from the estimated frequency.

Fig. 12 shows the performances under two-phase faults. At $\mathrm{t}=0.925 \mathrm{~s}$, a voltage sag of $50 \%$ appears in the phases $a$ and $b$ [Fig. 12(a)]. This voltage sag is also created by multiplying the voltage sensor gains of the phases $a$ and $b$ by 0.5 at time $0.925 \mathrm{~s}$. The filtered grid voltages and the unitary three-phase system are accurately estimated as shown in Figs. 12b and 12c, respectively. This result confirms the ability of the proposed method in extracting a sinusoidal and balanced unitary three-phase system from unbalanced and distorted three-phase voltages. In Fig. 12(d), the estimated voltage vector amplitude from the conventional PLL presents a considerable distortion, especially during fault conditions, compared with the signal provided by the AN-PLL. Moreover, the estimated utility frequency and the phase angle performed by the AN-PLL are insensitive to the fault, as shown in Figs. 12(e) and 12(f), respectively.

\section{EXPERIMENTAL VALIDATION OF THE AN-PLL IN THE GRID-CONNECTED DFIG DECOUPLED $P-Q$ CONTROL}

To experimentally validate the decoupled $P-Q$ control of the DFIG including the proposed AN-PLL, a test bench, which is realized in our laboratory, is used. DFIG control is conducted through a PWM converter connected to its rotor and feed from a battery system. The decoupled $P-Q$ control of the DFIG is implemented in the same dSPACE board used in the previous experiment. The control algorithm is implemented under MATLAB-Simulink with a sampling period of $0.25 \mathrm{~ms}$ and a Runge-Kutta (ode4) method resolution. The principle scheme of the experimental set up is shown in Fig 13. The parameters and characteristics of the controlled DFIG are presented in Appendix. In this section, the proposed AN-PLL associated with the DFIG control strategy is validated only in normal operating conditions (no frequency variations and no grid voltage disturbances).

Two tests are conducted. The first test is performed at negative stator active power $\left(P_{s}<0\right)$, and the second test is performed at negative stator reactive power $\left(Q_{s}<0\right)$. These two tests are preceded by a test at zero stator powers $\left(P_{s}=0\right.$, $Q_{s}=0$ ). During these tests, the DFIG is driven by a DC motor operating in open loop control. Hence, the rotor speed is likely changed when the DFIG provides stator power to the grid.

\section{A. Test at $P_{s}=0$ and $Q_{s}=0$}

Figs. 14 and 15 illustrate the obtained experimental results at zero stator active and reactive powers of the controlled DFIG, respectively. 


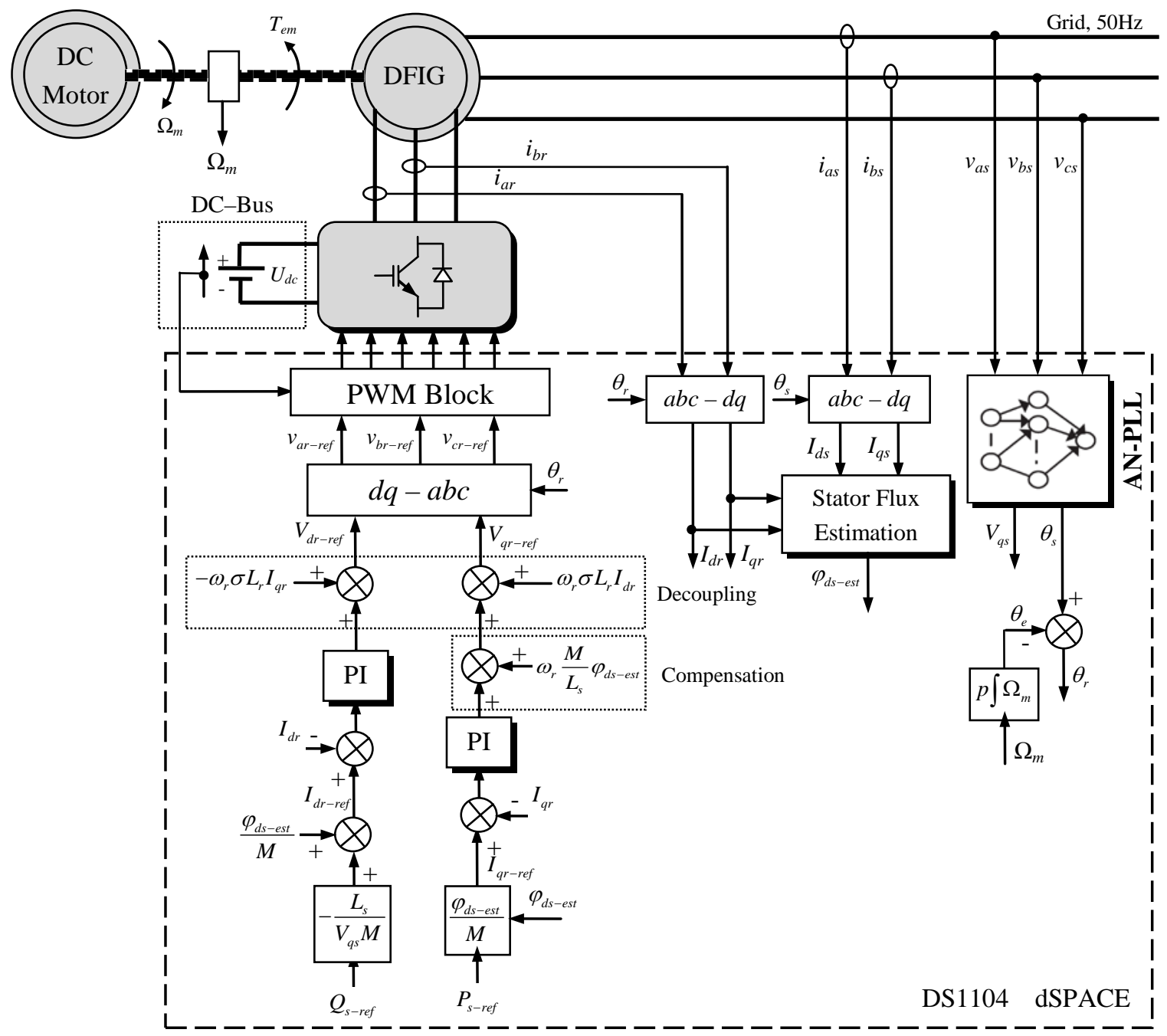

Fig. 13. Implementation scheme of the grid-connected DFIG decoupled $P-Q$ control strategy using the proposed AN-PLL.

The AN-PLL performances are shown in Fig. 14. The AN-PLL estimates accurately the pulsation [Fig. 14(a)], amplitude [Fig. 14(b)], and phase angle [Fig. 14(c)] of the grid voltage vector. These variables are used directly in the decoupled $P-Q$ control of the DFIG. The stator phase voltage of the DFIG is set to $110 \mathrm{~V}$, which is the half of the rated voltage.

The obtained results from the decoupled $\mathrm{P}-\mathrm{Q}$ control of the DFIG at zero stator active and reactive powers are illustrated in Fig. 15. Ps and Qs are regulated to zero, as shown in Fig. 15(a). In this test, the DFIG is driven at $1530 \mathrm{rpm}$ [Fig. 15(b)]. To obtain a zero stator power, the controllers apply a rotor voltage [Fig. 15(c)]. Hence, the quadratic rotor current (Iqr) is set to zero (therefore, Ps=0), and the direct rotor current (Idr) is maintained at a sufficient value for canceling the stator flux [Fig. 15(d)]. As a result, the stator currents become null [Fig. 15(e)].

\section{B. Test at $P s<0$ and $Q s=0$}

This test consists of applying a negative step of the active power reference (Ps-ref $<0$ ) to the DFIG stator to provide an active power to the grid. Fig. 16a shows that Ps follows perfectly the reference, whereas Qs is set to zero. The rotor speed decreased from $1530 \mathrm{rpm}$ to $1430 \mathrm{rpm}$ because of the resisting torque applied by the DFIG to the DC motor (Fig. 16b). Fig. 16c shows the rotor voltages calculated by the controllers to maintain $\mathrm{Qs}=0$ and $\mathrm{Ps}=-1 \mathrm{~kW}$. Fig. $16 \mathrm{~d}$ illustrates that the sudden change in the quadratic rotor current (Iqr) does not affect the direct rotor current (Idr), which demonstrates that $\mathrm{d}$-q-axis control is perfectly decoupled. The stator voltage and current of the phase a are shown in Fig. 16e. The current and voltage are in the phase opposition, which corresponds to $\mathrm{Ps}<0$ and Qs=0.

\section{Test at $Q_{s}<0$ and $P_{s}=0$}

This test is performed for a negative step in the reactive power reference $Q_{s}<0$ and $P_{s}=0$. Fig. 17a shows that the stator reactive power follows perfectly the reference $\left(Q_{\text {s-ref }}=-500 \mathrm{VAR}\right)$, whereas the stator active power is set to zero. The rotor speed of the DFIG decreases slightly when 


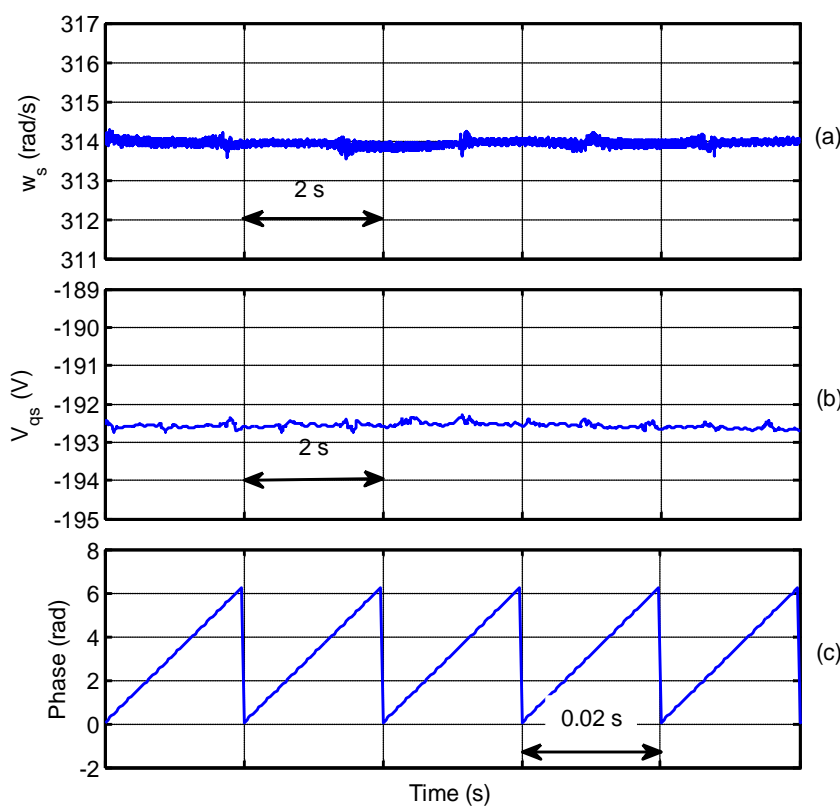

Fig. 14. AN-PLL performances: (a) stator voltage pulsation, (b) grid voltage vector amplitude, and (c) phase angle.

$Q_{s}<0$ (Fig. 17b). Fig. 17c gives the rotor voltages calculated by the controllers to obtain $P_{s}=0$ and $Q_{s}=-500 \mathrm{VAR}$. The rotor currents $I_{d r}$ and $I_{q r}$ are illustrated in Fig. 17d, where a perfect decoupling can be observed in the current control. The current $I_{q r}$ is set to zero, whereas the current $I_{d r}$ increases to $-11 \mathrm{~A}$ at $Q_{s}=-500 \mathrm{VAR}$. The stator voltage and current of the phase $a$ are given in Fig. 17e. This figure reveals that the current and voltage are in quadratic, which corresponds to $P_{s}=0$ and $Q_{s}<0$.

In the illustrated results, lower ripples of the currents and powers are observed. The signal quality can be achieved by increasing the PWM frequency, decreasing the sampling period $T_{e}$, and improving the accuracy of different sensors (current, voltage, speed sensors, etc.).

\section{CONCLUSIONS}

In this paper, an AN-PLL based on ADALINE for grid-connected DFIG control is proposed for the voltage vector amplitude, frequency, and phase angle estimation as an alternative to conventional PLL. The AN-PLL architecture is implemented using the dSPACE board and applied to a real power supply to prove its efficiency. A comparative experimental study between the proposed AN-PLL and the conventional PLL is also performed. According to the obtained experimental results, the proposed AN-PLL improves the robustness and steady state estimation performances. Hence, AN-PLL is a suitable synchronization system under severe utility conditions. Finally, experimental validation of the DFIG

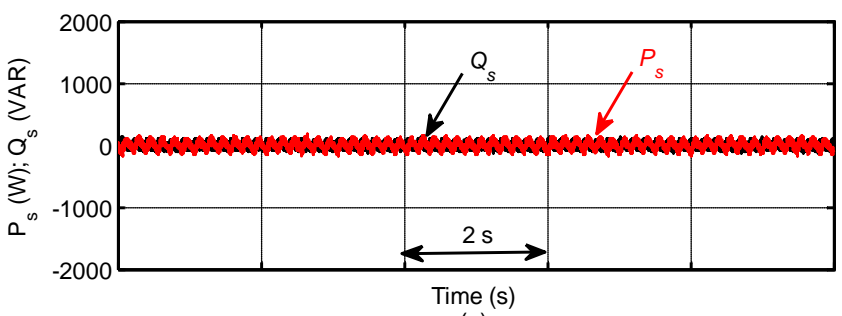

(a)

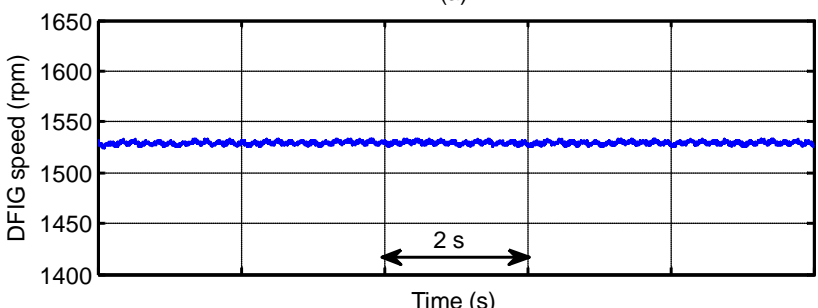

(b)

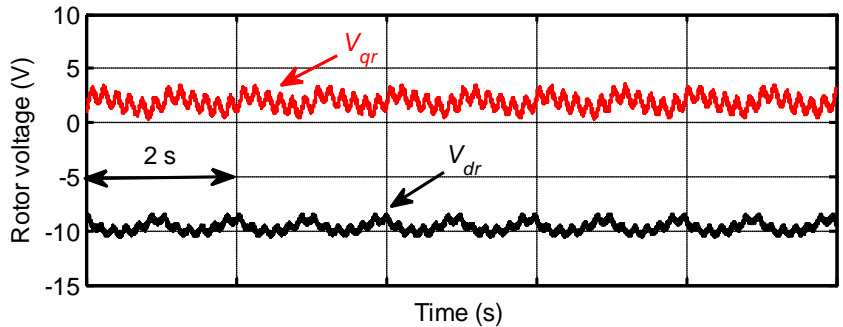

(c)

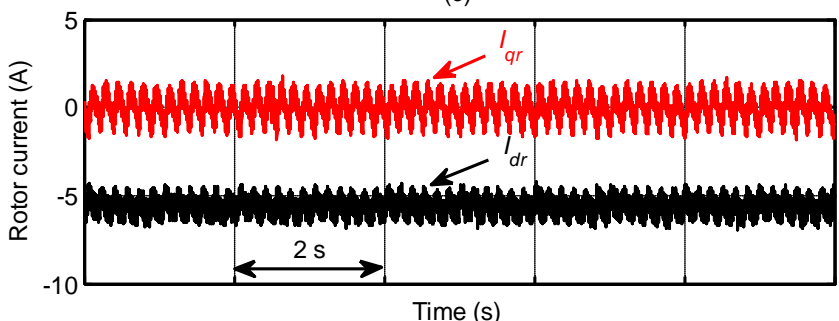

(d)

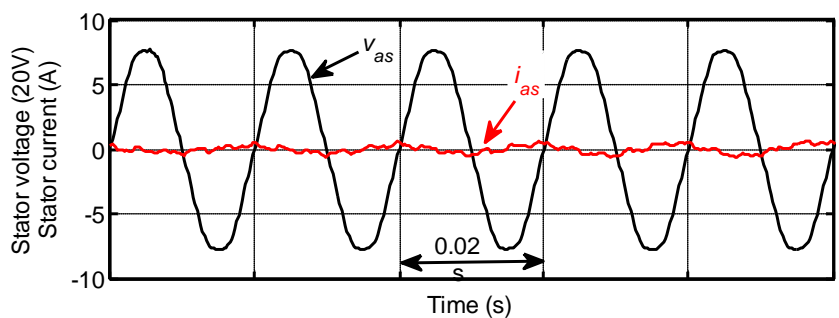

(e)

Fig. 15. Decoupling $P-Q$ control of the DFIG at $P_{s}=0$ and $Q_{s}=0$ : (a) stator active and reactive powers, (b) rotor speed, (c) rotor voltages, (d) rotor currents, and (e) stator voltage and current of the phase $a$.

decoupled $P-Q$ control using the new AN-PLL is conducted. The experimental results demonstrate the good performances of the AN-PLL included in the decoupled $P-Q$ control scheme of the DFIG. As future work, other experiments can be accomplished to test the proposed AN-PLL in DFIG control connected to disturbed grid voltages. 

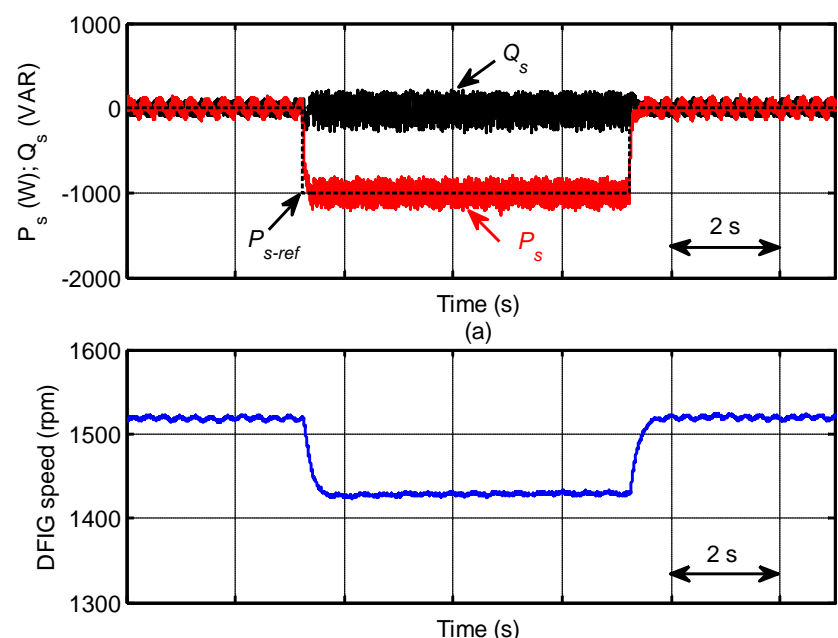

(b)

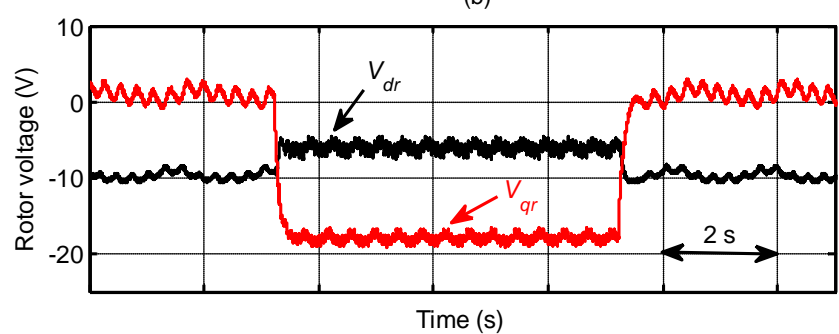

(c)

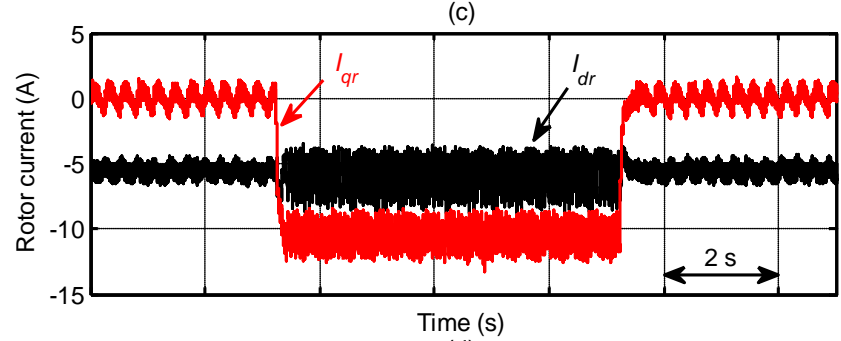

(d)

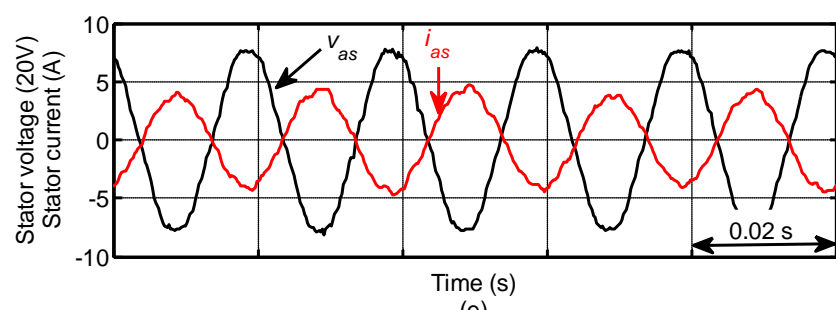

(e)

Fig. 16. Decoupling $P-Q$ control of the DFIG at $P_{s}<0$ and $Q_{s}=0$ : (a) stator active and reactive powers, (b) rotor speed, (c) rotor voltages, (d) rotor currents, and (e) $v_{a s}$ and $i_{a s}$ at $P_{s}<0$ and $Q_{s}=0$.

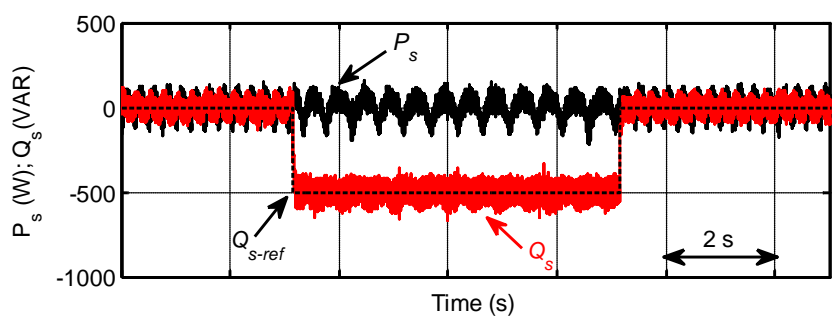

(a)

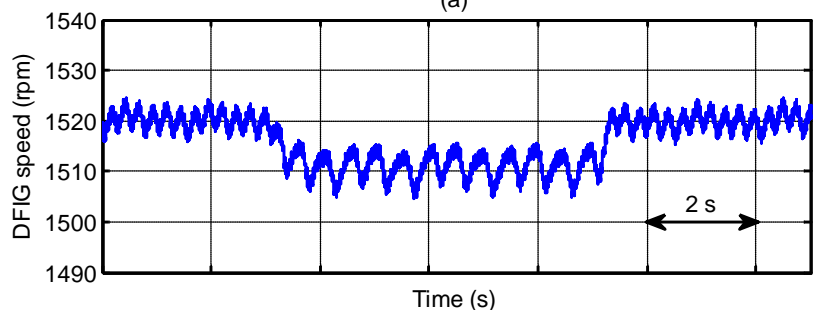

(b)

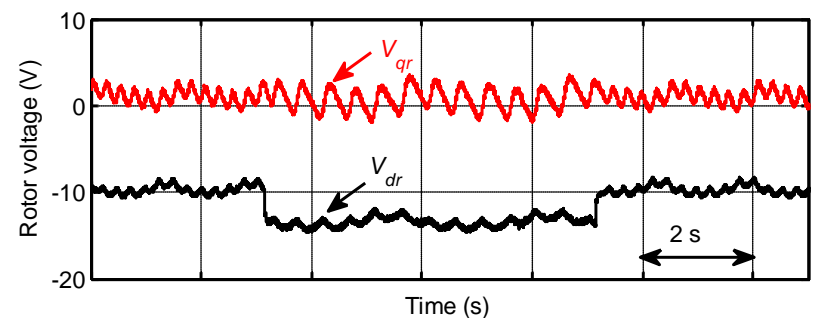

(c)

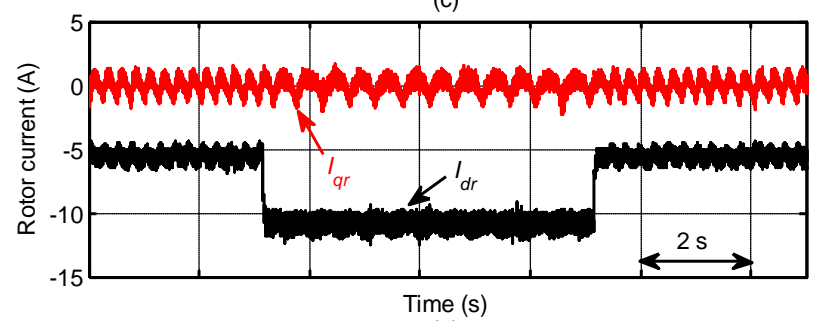

(d)

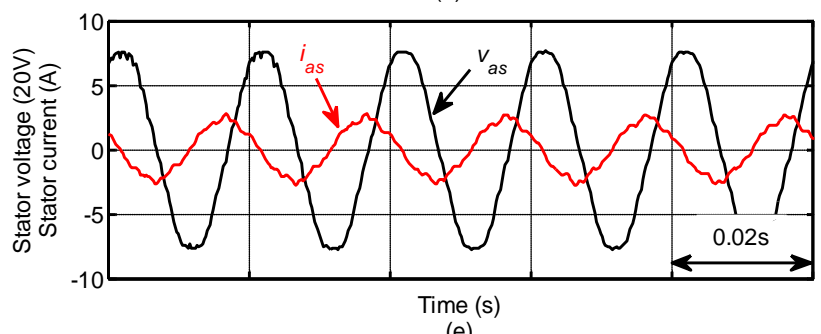

(e)

Fig. 17. Decoupling $P-Q$ control of the DFIG at $P_{s}=0$ and $Q_{s}<0$ : (a) stator active and reactive powers, (b) rotor speed, (c) rotor voltages, (d) rotor currents, and (e) $v_{a s}$ and $i_{a s}$ at $P_{s}=0$ and $Q_{s}<0$.

\section{APPENDIX}

Parameters and characteristics of the controlled DFIG.

$\begin{array}{ll}\text { Rated power } P_{n}(\mathrm{~kW}) & 3 \\ \text { Rated stator voltage } \Delta / \mathrm{Y} U_{s n}(\mathrm{~V}) & 220 / 380 \\ \text { Rated stator current } \Delta / \mathrm{Y} I_{s n}(\mathrm{~A}) & 11 / 6.3 \\ \text { Rated rotor voltage } \mathrm{Y} U_{r n}(\mathrm{~V}) & 180 \\ \text { Rated rotor current } I_{r n}(\mathrm{~A}) & 11 \\ \text { Rated speed } N_{n}(\mathrm{rpm}) & 1415\end{array}$

Number of pole pairs $p$ 2

Stator resistance $R_{S}(\Omega)$

1.5

Stator cyclic inductance $L_{s}(\mathrm{mH})$

220

Mutual inductance $\mathrm{M}(\mathrm{mH})$

109.8

Rotor resistance $R_{r}(\Omega)$

0.6

Rotor cyclic inductance $L_{r}(\mathrm{mH})$ 


\section{REFERENCES}

[1] A. Tapia, G. Tapia, J. X. Ostolaza, and J. R. Saenz, " Modeling and control of a wind turbine driven doubly fed induction generator,” IEEE Trans. Energy Convers., Vol. 18, No. 2, pp. 194-204, Jun. 2003.

[2] R. Pena, J. C. Clare, and G. M. Asher, "Doubly fed induction generator using back-to-back PWM converters and its application to variable-speed wind-energy generation,” IEE Proc.-Electr. Power Appl., Vol. 143, No. 3, pp. 231-241, May 1996.

[3] S. Muller, M. Deicke, and R. W. De Doncker, "Doubly fed induction generator systems for wind turbines," IEEE Ind. Appl. Mag., Vol. 8, No. 3, pp. 26-33, May-Jun. 2002.

[4] R. Datta, and V. T. Ranganathan, "Direct power control of grid-connected wound rotor induction machine without rotor position sensors," IEEE Trans. Power Electron., Vol. 16, No. 3, pp. 390-399, May 2001.

[5] F. Poitiers, T. Bouaouiche, and M. Machmoum, "Advanced control of a doubly-fed induction generator for wind energy conversion,” Electr. Power Syst. Res., Vol. 79, No. 7, pp. 1085-1096, Jul. 2009.

[6] R. Cardenas, R. Pena, J. Proboste, G. Asher, and J. Clare, "MRAS observer for sensorless control of standalone doubly fed induction generators," IEEE Trans. Energy Convers., Vol. 20, No. 4, pp. 710-718, Dec. 2005.

[7] F. M. Hughes, O. Anaya-Lara, N. Jenkins, and G. Strbac, "Control of DFIG-based wind generation for power network support," IEEE Trans. Power Syst., Vol. 20, No. 4, pp. 1958-1966, Nov. 2005.

[8] W. Qiao, W. Zhou, J. M. Aller, and R. G. Harley, "Wind speed estimation based sensorless output maximization control for a wind turbine driven a DFIG," IEEE Trans. Power Electron., Vol. 23, No. 3, pp. 1156-1169, May 2008.

[9] G. Abad, M. A. Rodriguez, G. Iwanski, and J. Poza, "Direct power control of doubly-fed-induction-generator-based wind turbine under unbalanced grid voltage," IEEE Trans. Power Electron., Vol. 25, No. 2, pp. 442-452, Feb. 2010.

[10] P. Rodriguez, J. Pou, J. Bergas, J. Ignacio Candela, R. P. Burgos, and D. Boroyevich, "Decoupled double synchronous reference frame PLL for power converters control,” IEEE Trans. Power Electron., Vol. 22, No. 2, pp. 584-592, Mar. 2007.

[11] Y. Han, L. Xu, M. M. Khan, G. Yao, L.-D. Zhou, and C. Chen, "A novel synchronization scheme for grid-connected converters by using adaptive linear optimal filter based PLL (ALOF-PLL)," Sim. Model. Practice and Theory, Vol.17, No. 7, pp. 1299-1345, Aug. 2009.

[12] E. Robels, S. Caballos, J. Pou, J. L. Martin, J. Zaragoza, and P. Ibanez, "Variable-frequency grid-sequence detector based on a quasi-ideal low-pass filter stage and a phase-locked loop,” IEEE Trans. Power Electron., Vol. 25, No. 10, pp. 2552-2563, Oct. 2010.

[13] F. Liccardo, P. Morino, and G. Raimondo, "Robust and fast three-phase PLL tracking system," IEEE Trans. Ind. Electron., Vol. 58, No. 1, pp. 221-231, Jan. 2011.

[14] Y. F. Wang and Y. W. Li, "Three-phase cascaded delayed signal cancellation PLL for fast selective harmonic detection," IEEE Trans. Ind. Electron., Vol. 60, No. 4, pp. 1452-1463, Apr. 2013.

[15] I. Carugati, S. Maestri, P. G. Donato, D. Carrica, and M. Benedetti, "Variable sampling period filter PLL for distorted three-phase systems,” IEEE Trans. Power Electron., Vol. 27, No. 1, pp. 321-330, Jan. 2012.
[16] F. González-Espín, E. Figueres, and G. Garcerá, “An adaptive synchronous reference-frame phase-locked loop for power quality improvement in a polluted utility grid," IEEE Trans. Ind. Electron., Vol. 59, No. 6, pp. 2718-2731, Jun. 2012.

[17] M. K. Ghartemani, S. A. Khajehoddin, P. K. Jain, and A. Bakhshai, "Problems of startup and phase jumps in PLL systems,” IEEE Trans. Power Electron., Vol. 27, No. 4, pp. 1830-1838, Apr. 2012.

[18] F. A. S. Naves, M. C. Cavalcanti, H. E. P. de Souza, F. Bradaschia, E. J. Bueno, and M. Rizo, "A generalized delayed signal cancellation method for detecting fundamental-frequency positive-sequence three-phase signals," IEEE Trans. Power Delivery, Vol. 25, No. 3, pp. 1816-1825, Jul. 2010.

[19] P. Rodriguez, A. Luna, R. S. Munoz-Aguilar, I. Etxeberria-Otadui, R. Teodorescu, and F. Blaabjerg, “A stationary reference frame grid synchronization system for three-phase grid connected power converters under adverse grid conditions," IEEE Trans. Power Electron., Vol. 27, No. 1, pp. 99-112, Jan. 2012.

[20] P. K. Dash, D. P. Swain, A. Routary, and A. C. Liew, “An adaptive neural network approach for the estimation of power system frequency,” Electr. Power Syst. Res., Vol. 41, No. 3, pp. 203-210, Jun. 1997.

[21] D. Halbwachs, P. Wira, and J. Mercklé, “Adaline-based approachs for time-varying frequency estimation in power systems,” in 2nd IFAC Int. Conf. Intelligent Control Systems and Signal Processing (ICONS2009), 2009.

[22] D. Ould Abdeslam, P. Wira, J. Mercklé, D. Flieller, and Y.-A. Chapuis, "A unified artificial neural network architecture for active power filters,” IEEE Trans. Ind. Electron., Vol. 54, No. 1, pp. 61-76, Feb. 2007.

[23] A. Bechouche, H. Sediki, D. Ould Abdeslam, and S. Haddad, "A novel method for identifying parameters of induction motors at standstill using ADALINE,” IEEE Trans. Energy Convers., Vol. 27, No. 1, pp. 105-116, Mar. 2012.

[24] H. Sediki, A. Bechouche, D. Ould Abdeslam, and S. Haddad, "ADALINE approach for induction motor mechanical parameters identification”. Mathematics and Computers in Simulation, Vol. 90, pp. 86-97, Apr. 2013.

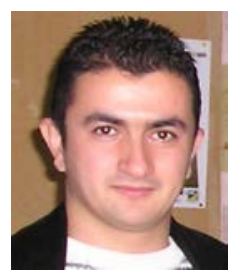

Ali Bechouche was born in Tizi-Ouzou, Algeria on December 09, 1982. He received Engineer, Magister, and Ph.D. degrees in electrical engineering from the Mouloud Mammeri University of Tizi-Ouzou, Tizi-Ouzou, Algeria in 2007, 2009, and 2013, respectively. He is currently an Associate Professor in the Department of Electrical Engineering, Mouloud Mammeri University of Tizi-Ouzou. His research interests include electrical drives and advanced techniques applied to wind energy conversion systems.

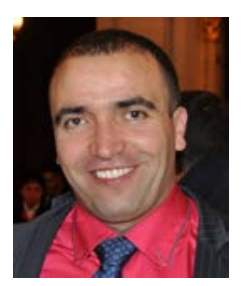

Djaffar Ould Abdeslam was born in Tizi-Ouzou, Algeria on April 20, 1976. He received M.Sc. degree in electrical engineering from the University of Franche-Comté, Besançon, France in 2002 and Ph.D. degree from the University of Haute-Alsace, Mulhouse, France in 2005. He is currently an Associate Professor in the University of Haute-Alsace. His research interest includes artificial neural networks applied to power active filters and power electronics. 


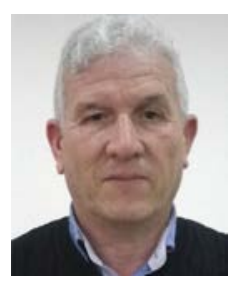

Tahar Otmane-Cherif was born in Tizi-Ouzou, Algeria on February 20, 1958. He received Magister and Ph.D. degrees in Electrical Engineering from the Mouloud Mammeri University of Tizi-Ouzou, Tizi-Ouzou, Algeria in 1994 and 2008, respectively. He is currently an Associate Professor in the Department of Electrical Engineering, Mouloud Mammeri University of Tizi-Ouzou. His research interests include electrical machines and wind energy conversion systems.

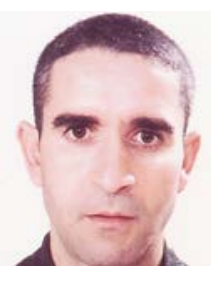

Hamid Seddiki was born in Tizi-Ouzou, Algeria on March 21, 1966. He received Engineer, Magister, and Ph.D. degrees in electrical engineering from the Mouloud Mammeri University of Tizi-Ouzou, Tizi-Ouzou, Algeria in 1991, 2000, and 2010, respectively. He received Accreditation to Supervise Research (Habilitation Universitaire) in electrical engineering from the Mouloud Mammeri University of Tizi-Ouzou in 2012. Since 1993, he has been with the Mouloud Mammeri University of Tizi-Ouzou, where he is currently an Associate Professor. His main interests include power electronics and electrical drives. 